SOCIEDADE BRASILEIRA DA PROFESSORES DE LINGUISTICA - SBPL XII ENCONTRO

No âmbito da $32^{\text {a }}$ Reunião Anual da Sociedade Brasileira para o Progresso da Ciência - SBPC, de 06 e 12 julho de 1980, realizou-se o XI Encontro de Professores de Lingüística, no Campus da Universidade Estadual do Rio de Janeiro, com a seguinte programação:

\title{
MESA REDONDA
}

Segunda-feira, 7 de julho de 1980

das $8: 00$ às 10:30 horas, sala $7050 / 7056$

LINGUíSTICA E ALFABETIZAÇÃO DE ADULTOS: MÉTODOS E CONFRONTOS LINGUISTICOS - IDEOLÓGICOS.

Coordenador: Maria do Socorro Silva de Aragão (Universidade Federal da Paraíba) Participantes: A. Kosc (MOBRAL - Rio de Janeiro); I. Passoni (Secretaria de Educação e Cultura do Estado de São Paulo e Universidade de São Paulo) e J. J. Peralta (Faculdades Integradas Princesa Izabel)

\section{SIMPÓSIO}

Terça-feira, 8 de julho de 1980

das $15: 00$ às $18: 00$ horas, sala 7050/7056

LINGUAGEM, IDEOLÓGICA E EDUCAÇÃO: CONTRIBUIÇÃO DA LINGỨSTICA PARA A CONSTRUÇĀO DE UMA SOCIEDADE DEMOCRÁTICA

Coordenador: Eduardo Peñuela Cañizal (Universidade de São Paulo) A linguagem e o seu papel no processo democrático.

Expositores: E. Lopes (Universidade Estadual Paulista) Linguagem e ideologia; H. Villares (Universidade de São Paulo) Linguagem e insconsciente no processo da educação; e A.M.B. Ortiz (Universidade de São Paulo) Objeto, signo, valor e linguagem. 
SESSĀO DE COMUNICAÇÃO COORDENADA

SOCIEDADE BRASILEIRA DE PROFESSORES DE LINGUISTICA

Quarta-feira, 9 de julho de 1980

das 8:00 às 10:30 horas, sala 7050/7056

\section{LINGUÚSTICA E TECNOLOGIA DA EDUCAÇÃO}

Presidente: Regina Célia Pagliuchi da Silveira

I.G.V Koch (31-B.9) Lingüística e produção de textos.

R. Buongerminio (32-B.9) Fenômenos fonéticos constatados a partir da acentuação em português.

R.C.P da Silveira e C.C.P Leite (33-B.9) Signos linguísticos e uma gramática textual do português.

J.H.S. de Siqueira (34-B.9) Uma revisão crítica de um método de ensino de redação aplicado em alunos universitários.

L.T Martins (35-B.9) Novas perspectivas para o ensino da ortografia.

\section{SIMPÓSIO}

Quarta-feira, 9 de julho de 1980

das $15: 00$ às $18: 00$ horas, sala $7050 / 7056$

DISCURSO PEDAGógICO, DISCURSO CIENTIFFICO E DISCURSO BUROCRÁTICO NA UNIVERSIDADE - CONFRONTO E MANIPULAÇÃO

Coordenador: Cidmar Teodoro Pais (Universidade de São Paulo) Linguagem, estruturas de poder e manipulação nas instituições.

Expositores: M.P Rector (Pontifícia Universidade Católica do Rio de Janeiro) Meta-censura da linguagem; E. Neiva Junior (Universidade Federal Fluminense) Linguagem e produção de ideologia; J. de F. Forbes (Núcleo de Ensino em Psiquiatria e Psicologia) Linhagem, instituição e repressão.

\section{ASSEMBLÉIA}

Quarta-feira, 9 de julho de 1980

às 18:00 horas, sala 7015/7019

\section{SESSÃO DE COMUNICAÇÃO COORDENADA}

Quinta-feira, 10 de julho de 1980

das 8:00 às 10:30 horas, sala 7050/7056 


\section{LÍNGUA PORTUGUESA E ENSINO}

Presidente: Leonor Lopes Fávero

L.L. Fávero e E.M. Barian (26-B.9) Implicações sintático - semânticas na análise de orações, na unidade maior: o texto.

M.E.M.Z. Baptista (27-B.9) Contribuição à pedagogia da língua portuguesa.

M.C.P de S. e Silva (28-B.9) Dificuldades na produção escrita de orações relativas.

L.F de Azevedo (29-B.9) O problema da seleção lexical em redações de alunos universitários.

M.I.S. de M. Franco (30-B.9) Estudo do comportamento lingüístico no pré-escolar.

\section{SESSÃO DE COMUNICAÇÃO COORDENADA}

Sexta-feira, 11 de julho de 1980

das 8:00 às 10:30 horas, sala 7050/7056

\section{VOCAÇÃO INTERDISCIPLINAR DA LINGUUISTICA}

Presidente: José Jorge Peralta

J.J. Peralta (20-B.9) A lingüística e a análise de textos literários - seus valores e limitações.

M.A. Barbosa (22-B.9) Tipologia dos processos de produtividade léxica.

C.T. Pais (23-B.9) Transcodificação e produção de ideologia.

E.P Cañizal (48-B.9) A prática democrática do significante artístico.

M.S. Fonseca e R. Avelar - Uma experiência no campo de tecnologia aplicadas à educação: Considerações sobre a percepção do código escrito e código oral.

\section{MESA REDONDA}

Sábado, 12 de julho de 1980

das 8:00 às 10:30 horas, sala 7050/7056

\section{LINGUAGEM DOCUMENTÁRIA E ACESSO À INFORMAÇÃO}

Coordenadora: Maria de Fátima Gonçalves Moreira Talaro (Universidade de São Paulo)

Participantes: J.B. de Assumpção (Universidade de São Paulo); M.A. Barbosa (Universidade de São Paulo) e C.T. Pais (Universidade de São Paulo). 